Joshua M. Pearce, Sara J. Johnson, and Gabriel B. Grant, "3D-Mapping Optimization of Embodied Energy of Transportation", Resources, Conservation and Recycling, $\mathbf{5 1}$ pp. 435-453, 2007.

\title{
3D-Mapping Optimization of Embodied Energy of Transportation
}

\author{
Joshua M. Pearce ${ }^{1}$, Sara J. Johnson ${ }^{1}$, and Gabriel B. Grant ${ }^{2}$ \\ ${ }^{1}$ Clarion University of Pennsylvania, Physics Department, Clarion, PA 16214 \\ ${ }^{2}$ Purdue University, West Lafayette, Indiana
}

\author{
Corresponding Author: \\ Joshua M. Pearce \\ Assistant Professor of Physics \\ 106 Peirce Science Center \\ Clarion University of Pennsylvania \\ Clarion, PA 16214-1232 \\ Tele: 814-393-2713 \\ Fax: 814-393-1630 \\ jpearce@clarion.edu
}


Joshua M. Pearce, Sara J. Johnson, and Gabriel B. Grant, "3D-Mapping Optimization of Embodied Energy of Transportation", Resources, Conservation and Recycling, 51 pp. 435-453, 2007.

\title{
3D-Mapping Optimization of Embodied Energy of Transportation
}

Joshua M. Pearce ${ }^{1}$, Sara J. Johnson ${ }^{1}$, and Gabriel B. Grant ${ }^{2}$

${ }^{1}$ Clarion University of Pennsylvania, Physics Department, Clarion, PA 16214

${ }^{2}$ Purdue University, West Lafayette, Indiana

\begin{abstract}
The recent development of Google Earth, an information service that provides imagery and three dimensional data depicting the entire Earth, provides an opportunity to use a new method of navigating information to save energy in the real world. Google Earth uses Keyhole Markup Language (KML) for modeling and storing geographic features and information for display in the Google Earth Client. This paper will analyze the potential of this novel and free geographic mapping service to reduce embodied energy of transportation in two ways. First, at the consumer level, Google Earth will be studied to map the automobile route that uses the least fuel and maintains vehicles at their individual maximum fuel efficiency velocities. The same analysis for single destination trips could be used to optimize fleet vehicle routes such as garbage or recycling collection trucks. The secondary benefit of ecological education will also be explored. Fuel used could be converted into monetary units based on the current price of gas, pollution/ greenhouse gas emissions, or ecological footprints to improve driving habits. Secondly, KML overlays will be analyzed for use of determining: i) raw material and products availability as a function of location, and ii) modes of transportation as a function of emissions. These overlays would enable manufacturers access to an easily navigable method to optimize the life cycle of their products by minimizing transportation embodied energy. The most efficient transportation methods and travel routes could be calculated. This same tool would be useful for architects to obtain Leadership in Energy and Environmental Design rating points for the green design of buildings. Overall, the analysis completed finds that the flexibility and visual display of quantitative information made available by Google Earth could have a significant impact at conserving fuel resources by reducing the embodied energy of transportation on a global scale.
\end{abstract}

\section{Keywords}

ecological education, embodied energy, fuel conservation, greenhouse gas emissions, LEED, mapping, route optimization, transportation energy, transportation

\section{Introduction}

Over eighty percent of our global energy needs are met by the combustion of fossil fuels (Ristinen and Kraushaar, 1999) and by far the most important type of energy source for the functioning of our global economy is petroleum (Yergin, 1992). Over the past forty years, the number of newly-found oil reserves has been slowly diminishing (Bentley, 2002). Some energy analysts warn that globally, society is approaching "peak oil", 
Joshua M. Pearce, Sara J. Johnson, and Gabriel B. Grant, "3D-Mapping Optimization of Embodied Energy of Transportation", Resources, Conservation and Recycling, 51 pp. 435-453, 2007.

where the maximum long-term rate of extraction and depletion of conventional petroleum is reached (although the exact time of peak oil is hotly debated). There are still billions of barrels of oil left underground, and as the price of oil climbs, when supply cannot meet demand, other vast sources of petroleum will become economically exploitable (e.g. Alberta has about 178 billion barrels of proven oil reserves in oil sands (National Energy Board, 2005)). Unfortunately, this does not present a solution, because the emissions from burning these fuels would represent an unacceptable risk to the vitality of the earth because of global climate destabilization and thermal forcing (Hansen et al., 2000; Hoffert, et al., 2002; Rose, 1979; Thomas et al., 2004). It is now clear that there needs to be more attention paid to how the fossil fuels are being used, particularly for transportation and more rapid adoption of methods to reduce fossil fuel combustion.

The recent development of Google Earth, a geographical information service that provides satellite imagery and three dimensional (3D) data depicting the entire planet, creates an opportunity to reduce energy consumption for transportation. This paper will explore the viability of this novel and free geographic mapping service to reduce embodied energy of transportation. The embodied energy of transportation refers to the transportation component of the embodied energy, where embodied energy is the quantity of energy required to manufacture and supply to the point of use of a product, material or service. At the consumer level, Google Earth could be used to map the automobile route that uses the least fuel between two locations. It can also be used to optimize fleet vehicle routes in terms of energy and emissions for vehicles such as mail carriers, garbage or recycling collection trucks. This information for transportation energy optimization will help not only conserve fuel, but also can incorporate ecological education features geared toward changing behaviors in vehicle users. Additionally, overlays in Google Earth could be developed first nationally and then on a planet-wide basis of i) raw material and product availability as a function of location and ii) modes of transportation as a function of emissions. These overlays would enable manufacturers to minimize the life cycle energy costs of their finished products by access to an easily navigable method to determine embodied energy of transportation for a given product or raw material. This same information could be utilized to develop symbiosis in industrial ecologies. Finally, this information would also be useful for architects trying to reduce the embodied energy in their designs of green buildings.

\section{Background}

Physical energy use and resultant emissions from combustion of fossil fuels is steadily becoming of greater importance to decision makers at both macro and micro levels. This is largely driven by the consensus among the 2004 Intergovernmental Panel on Climate Change (IPCC) and the 1993 World Energy Council's Global Energy Scenarios to 2050, that if current trends continue in climate destabilization, our Earth will reach a point of no 
Joshua M. Pearce, Sara J. Johnson, and Gabriel B. Grant, "3D-Mapping Optimization of Embodied Energy of Transportation", Resources, Conservation and Recycling, 51 pp. 435-453, 2007.

return (Hoffert, et al., 2002). Global climate destabilization is primarily due to the combustion of fossil fuels for energy and the resultant greenhouse gas (GHG) emissions (IPCC, 1995; IPCC, 2001). Global warming is already occurring, and if combustion of fossil fuels continues, temperatures are projected to rise $1.4^{\circ} \mathrm{C}$ to $5.8^{\circ} \mathrm{C}$ in the next 100 years (Penner, 2004; Stocker, 2004). A rise in temperatures could lead to the melting of glaciated ice sheets, raising the sea level up to 7 meters, and flooding many important coastal cities (Gregory, Huybrechts, and Raper, 2004; Schiermereier, 2004). Diseases such as cholera, malaria, and dengue fever show correlations to specific climate patterns that would be aggravated by increases in global average temperatures (Kovats, et al., 1999; Koelle, et al., 2005). Summer heatwaves will also increase (Schar, et al., 2004). An increased temperature will also affect many plants and animals. It is projected that migration routes will change (Krajick, 2004), the $\mathrm{pH}$ levels in the oceans will drop (Caldeira, and Wickett, 2003), and extinction rates will increase (Thomas, et al., 2004). Studies have also shown that increased carbon dioxide $\left(\mathrm{CO}_{2}\right)$ will eventually slow down the nitrogen fixation rates of plants (Hungate, et al., 2004). Despite these consequences, $\mathrm{CO}_{2}$ emissions from the combustion of fossil fuel have consistently been increasing. In the U.S. in 2004, $\mathrm{CO}_{2}$ emissions from the burning of fossil fuels increased $1.5 \%$ (U.S. EPA, 2006). In 2004, the largest source of $\mathrm{CO}_{2}$ emissions $\left(2,438 \mathrm{Tg}\left(10^{6}\right.\right.$ metric tons) or 43\%) came from burning petroleum, the majority of which was used for transportation (U.S. EPA, 2006). The consequences of our continued and escalating fossil fuel combustion for transportation are clearly unacceptable.

Although all aspects of industrialized society currently depend on enormous influxes of fossil fuel-based energy, transportation is now taking a dominant position. As can be seen in Table 1, the relative importance of transportation-caused emissions over the other main end-use sectors (industrial, residential, commercial) has increased from 1990, when the baseline emissions standards were defined for the Kyoto Protocol. Now, transportation makes up the largest percentage, representing one third of all anthropogenic emissions. In 2003 , over $27 \%$ of the United States' total consumption of energy was used to transport goods and people (U.S. Department of Energy, 2004). This energy, which comes to 26.9 quadrillion $\left(10^{15}\right)$ BTUs per year is increasing at an average rate of $1.9 \%$ per year (U.S. Department of Energy, 2004).

All current transportation modes result in GHG emissions. The $\mathrm{CO}_{2}$ emissions from fossil fuel combustion used in transportation for 2004 can be seen in Table 2. Gasoline combustion dominates transportation emissions comprising $60 \%$ of the total while diesel combustion and jet fuel combustion produce 23 and 12 percent of the $\mathrm{CO}_{2}$ emissions respectively. Gasoline and diesel fuel for automobiles have been increasing substantially. Together, they increased from $77 \%$ of fuel used to $83 \%$ from 1990 to 2004 , as can be seen in Table 2. 
Joshua M. Pearce, Sara J. Johnson, and Gabriel B. Grant, "3D-Mapping Optimization of Embodied Energy of Transportation", Resources, Conservation and Recycling, 51 pp. 435-453, 2007.

The physical reality of energy use is often ignored when transportation methods are chosen and thus it is not surprising that the total energy used for transportation from 1990 to 2004 increased by $24 \%$ as can also be seen in Table 2 . In the past, when humanity governed over what appeared to be an inexhaustible fossil fuel energy supply, and the consequences of its harvest were unknown, it was tolerable to use as much energy as could be extracted economically as rapidly as possible. This is no longer acceptable being that GHG emissions must not increase, but actually be cut to stabilize the global climate. In addition, because energy is needed to fabricate sustainable energy sources such as solar photovoltaics (Pearce, 2002) it appears prudent to try to optimize our use of fossil fuels today. Even small individual reductions in energy use have significant impact when aggregated across the U.S. economy (Pearce and Hanlon, 2006). One opportunity to resolve these challenges in small steps is to minimize transportation energy for single and multi-destination travel routes as well as the embodied energy of transportation in manufactured products. The energy conservation measure studied here is to reduce the embodied energy of transportation by optimizing routes using the Google Earth client.

\section{Material Studied: Google Earth as an Embodied Energy of Transportation Tool} Google Earth utilizes Keyhole Markup Language (KML), an Extensible Markup Language (XML) grammar and file format for modeling and storing geographic features, such as points, lines, images and polygons for display in the Google Earth Client. XML is a World Wide Web Consortium (W3C) initiative that allows information and services to be encoded with meaningful structure and semantics that both humans and computers can comprehend. Google Earth contains satellite images of the entire planet as well as topographical information. The resolution of the satellite images is variable, but for some locations the images are so detailed it allows for three dimensional buildings' information. Users of Google Earth can already search for locations and map directions to and from specific locations. The open architecture of the software also allows users to measure distances by creating paths and marking them with customized polygons, utilize their own photos and overlay them upon the provided geographic images, and add specific "placemarks" to locations showing data and links to other sites and files (Google, 2006). The overlays and placemarks serve as a visual Yellow Pages, not only listing the contact information but showing the actual location and directions on a map. Google Earth represents a new way for the information on the internet to be organized by location rather than specific search terms or directories.

Google Earth relays geographic information in an understandable way to average computer users. For example, it allows users to pull up overlays of hotels, restaurants, hospitals, gas stations, schools, and banks over a specific geographic area of interest that are hyperlinked to the establishments' websites and contact information. The applications 
Joshua M. Pearce, Sara J. Johnson, and Gabriel B. Grant, "3D-Mapping Optimization of Embodied Energy of Transportation", Resources, Conservation and Recycling, 51 pp. 435-453, 2007.

for Google Earth are growing rapidly and new programs and overlays are created every day. For example, Google Earth images recently lead to the accidental discovery of an ancient roman villa by a computer programmer (Butler, 2005). Google Earth has also been used for creating am interactive map of England's Strategic Health Authorities (Boulos, 2005) and proved effective at mapping disaster zones during relief efforts in New Orleans and Pakistan (Nourbakhsh et al., 2006). The program is regularly being used by many major television stations including $\mathrm{ABC}$ and $\mathrm{CNN}$ as an easy method of visually identifying the geographic location of news from all over the globe. One can even track the real-time progress of airplanes, including their altitude and speed (e.g. www.fboweb.com).

Google Earth could also be utilized as an ecological tool. The standard program already includes geographic overlays showing the location of rivers, lakes, mountain ranges, earthquakes, and volcanoes. These overlays could be taken a step further to include pollution data, air quality, radioactive isotope counts, acid rain, ground level ozone, water quality, UV indices, migration paths of endangered species, and local sources of food (farms, community supported agriculture (CSAs), co-ops, etc). There are already sources of local information about pollution such as www.scorecard.org. In addition, the European Environment Agency has already begun a project entitled "In Your Neighborhood", which will allow the public to view real-time air pollution amounts over various European countries (Biever, 2005). Applications such as these enable users to avoid pollution. By using the power of Google Earth to optimize routes and reduce embodied energy for transportation, users will prevent pollution.

\section{Technique 1: Route Optimization}

Currently the use of internet mapping software is growing in popularity. Sites such as maps.google.com, maps.yahoo.com/dd, mapquest.com, etc. offer driving directions free of charge for individuals planning trips in the U.S. and abroad. Users type in their current location and destination addresses and a map is formulated with a route and directions for travel. This information is also available for travel software packages and global positioning systems (GPS) to help travelers navigate while driving (e.g. the current model of the Toyota Prius). Currently, the route mapping software is optimized to reduce travel time assuming optimal traffic. Future embodiments could include incorporating traffic and construction delays into routes optimized for time. However, as oil prices continue to climb to record levels and climate change becomes increasingly important in the public consciousness, optimization of routes for fuel use is likely to become more important. Google Earth could be used to assist travelers going to a single destination, to determine the best route, based upon fuel use. 
Joshua M. Pearce, Sara J. Johnson, and Gabriel B. Grant, "3D-Mapping Optimization of Embodied Energy of Transportation", Resources, Conservation and Recycling, 51 pp. 435-453, 2007.

A first approximation for optimizing fuel use in transport is to minimize the distance traveled; however, determining the optimal fuel use for a given route is dependent on several factors: i) distance, ii) type of road, iii) speed, iv) elevation changes and v) type of vehicle and loading of the vehicle. For example, with the exception of fuel-electric hybrid vehicles, traveling at slower speeds from an optimum of around $72 \mathrm{~km} / \mathrm{hr}(45 \mathrm{mph})$ for a standard automobile can actually decrease mileage. Similarly, the combination of loading and elevation changes can have a profound effect on the amount of fuel needed to transport goods a given distance.

For fleet vehicles, routes can become even more important. Although the embodied energy of transportation from waste recovery and recycling is small compared to the energy used for the entire transportation sector (Hunhammar, 1995), numerous studies have been conducted to optimize routes for garbage collection, recycling collection, school bus pick-ups, etc. (Angelelli and Speranza, 2002; Ballou, 1990; Bowerman, 1995; Nuortioa, et al., 2006; Pattnaik et al., 1998; Sahoo, et al., 2005; Suh and Rousseaux, 2002; Wang, et al., 1995). Most of these large fleet vehicles have very low fuel efficiencies and have more polluting diesel engines. There are around 179,000 garbage/recycling trucks in use in the U.S. (INFORM, 2006). These garbage trucks have some of the lowest fuel efficiencies of all motorized vehicles, around 3 miles per gallon (mpg) (2006). Currently, the average truck travels approximately 25,000 miles per year and burns 8,300 gallons of diesel fuel (INFORM, 2006). In the case of fleet vehicle routes, all of the same information would be utilized as in the single destination case, but the route would be optimized for all stops along the path, from the initial to the final destinations. There is extensive, but not exhaustive, use of expensive custom geographic information system (GIS) software to map routes for school buses and garbage trucks. Energy, however, is not always the factor minimized and the tool discussed here offers the possibility of real time overlays being created showing traffic lights and construction zones, which could be modified according to traffic patterns to minimize unnecessary idling of fleet vehicles. An example of this type of overlay can be seen in Figure 1, which shows a Google Earth hybrid satellite photo/street map image of the Borough of Clarion in Pennsylvania. The circles indicate traffic lights. Some "onboard" GPS-based systems already download traffic information in real time, and it is possible these packages could incorporate elevation into their algorithms. These GIS packages, however, are very expensive and an open-source advanced version of the Google Earth tool could be updated in real time to indicate optimal routes based not only on time, but also on energy (or fuel costs).

\section{Results and Discussion for Technique 1:}

\section{A. Route and Vehicle Velocity Optimization}


Joshua M. Pearce, Sara J. Johnson, and Gabriel B. Grant, "3D-Mapping Optimization of Embodied Energy of Transportation", Resources, Conservation and Recycling, 51 pp. 435-453, 2007.

In addition to determining the optimal route, using the Google Earth program in vehicles in real time would enable drivers to chart a course that maintains their vehicle at its individual maximum fuel efficiency speed. The operating efficiency of modern automobiles is complex. For a standard automobile powered with an internal combustion engine, the efficiency of the engine improves as it accelerates from rest $(0 \mathrm{~km} / \mathrm{hr})$, because it uses a fixed amount of fuel to power itself and the accessories, and a variable amount of fuel dependent on the power required to keep the automobile going at a given speed. As the vehicle is accelerated to higher velocities, the automobile overcomes the rolling resistance of the tires and friction in the vehicle's other components (e.g. friction in the wheel bearings). So in terms of fuel used per unit distance, the faster the vehicle goes at first, the better use it makes of that fixed amount of fuel required; however, once the speed gets up into the $80 \mathrm{~km} / \mathrm{hr}(50 \mathrm{mph})$ range, each increase in speed represents an increase in power required, mostly to overcome wind resistance. Eventually, the power required increases more than the efficiency of the engine improves. At this point, the mileage starts falling and can drop substantially after $88.5 \mathrm{~km} / \mathrm{hr}(55 \mathrm{mph})$, as can be seen in Fig. 2. For example, a car that decreases its speed from $120.7 \mathrm{~km} / \mathrm{hr}$ ( $75 \mathrm{mph})$ to 105 $\mathrm{km} / \mathrm{hr}(65 \mathrm{mph})$ is increasing its fuel efficiency by $4.4 \mathrm{mpg}$. It should be pointed out here that these estimates are conservative because the optimal efficiency as shown in Fig 1 was for cars in 1997. The U.S. automobile fuel efficiency actually declined through the 1990's and is at present relatively level (Heavenrich, 2006). This is mostly due to the increased use of fuel-inefficient sports utility vehicles (SUVs). So although fuel efficiency of cars increased modestly, the increased use of light-duty trucks and SUVs dragged down the combined fuel efficiency of the fleet (Heavenrich, 2006). Such SUVs and light trucks have i) a drag coefficient about twice that of more aerodynamic cars, ii) more than double the frontal area of small cars, and iii) can weigh two to three times more than cars. In general, smaller, lighter, more aerodynamic cars will get their best mileage at higher speeds than SUVs. Bigger, heavier, more cumbersome and less aerodynamic vehicles will get their best mileage, which is still relatively poor, at lower speeds. The optimal velocity for any given vehicle would change depending on the mass of the cargo it was carrying and the grade and surface the automobile was traveling over. Advanced versions of this technique in future automobiles could include weight sensors and road condition sensors in order to better optimize automobile travel efficiencies.

\section{B. Ecological Education of Drivers}

The route optimization tool will have a secondary benefit by encouraging more efficient driving. Already, in some automobiles, there are real time fuel efficiency gauges that encourage better driving habits (McKibbon, 2003). For consumers, the Google Earth Transportation Optimization Tool would not only reduce fuel costs, but also enable consumers to better understand the externalities associated with their travel. Gallons or liters of fuel use calculated by the tool could be converted into i) monetary units based on 
Joshua M. Pearce, Sara J. Johnson, and Gabriel B. Grant, "3D-Mapping Optimization of Embodied Energy of Transportation", Resources, Conservation and Recycling, 51 pp. 435-453, 2007.

the current price of gas, ii) pollution based on the emissions tests of the individual vehicle or iii) GHG emissions (e.g. with each gallon of gasoline burned, 19.56 pounds of $\mathrm{CO}_{2}$ are released into the atmosphere (Energy Information Administration, 2006)). Consumers could have an immediate feedback as to how their trips influenced global climate conditions.

A more intuitive learning aid might incorporate the concept of ecological footprints developed by Wackernagel and Rees (1994). A transportation method's aggregate ecological footprint is a measure of the productive land area needed to support indefinitely in a sustainable manner all the material input and disposal needs of that transportation mode. Everything that the transportation method consumes (energy in the form of gasoline, materials like lubricants, etc.) has a footprint that can be expressed in terms of land area. For example, a diesel-powered truck could be powered from biodiesel obtained from sustainable agricultural practices on land used to grow switchgrass (Panicum virgatum). The ecological footprint would be the land area needed to grow the quantity of switchgrass to make the necessary amount of biodiesel fuel. In this way, an ecological footprint is a value that represents the amount of resources used in comparison to those that are actually available (Pearce, et al., 2001; Chi and Stone, 2005). Along with the data, a calculated ecological footprint that represents the amount of resource used in comparison to those available could be mapped on Google Earth. This would allow drivers to "see" how much land area would be needed to fuel their particular trips. For example, using the mileage and efficiency of the average garbage truck in the U.S., the land area needed to sequester the $\mathrm{CO}_{2}$ emissions from using 8,300 gallons $(31,400 \mathrm{~L})$ of gasoline is about 10.99 hectare/year. This ecological footprint area was determined following the method used by Chi and Stone (2005). There are approximately 136,000 of these trucks in the U.S. making the total needed land area about 1.5 million hectare/year. This can be visually displayed in Google Earth as roughly the total land area of Connecticut as seen in Figure 3. It should be noted, that in today's society where the vast majority of diesel used today is not biodiesel using land area as a measure of vehicle fuel requirements may at first appear difficult to comprehend. However, if society is going to make the transition to a sustainable state a shift in the way that standard problems are viewed is necessary. The ecological footprint reference frame provides one such method that can be understood by decision makers because it sets clear limits (e.g. the area of the earth) needed for sustainability to be reached.

\section{Technique 2: Minimization of the Embodied Energy of Transportation of Products}

To determine a product's environmental impact, it is necessary to perform a comprehensive life cycle analysis (LCA). LCA quantifies how much energy and raw materials are used and how much (solid, liquid, and gaseous) waste is generated at each stage of a product's life (Ayres, 1995; Pearce and Lau, 2002). Ideally, an LCA would 
Joshua M. Pearce, Sara J. Johnson, and Gabriel B. Grant, "3D-Mapping Optimization of Embodied Energy of Transportation", Resources, Conservation and Recycling, 51 pp. 435-453, 2007.

include quantification of material and energy needed for: raw material extraction, manufacturing of all components, use requirements, generation (if any), disposal or recycling, and the distribution/transportation in-between each stage. Complete LCA's are difficult to perform in part because of the lack of quantifiable data for embodied energy of transportation (González, Adenso-Díaz, and González-Torre, 2002). Here a method is analyzed that utilizes Google Earth to both determine and then optimize the embodied energy from transportation in products.

Using preexisting aerial photography in the (GIS) of Google Earth, specific locations can be pinpointed and overlays containing any type of information can be created. For Google Earth to be used as an ecological navigational tool for manufacture's and consumers, a comprehensive overlay that maps the location of raw materials and products needs to be developed. There should be subcategories within this overlay listing locations of different types of materials. Within each placemark on the overlay, the contact information for each specific manufacture is easily made available. The placemark should also include information about the products and hyperlinks to websites. This will allow consumers to choose the products they want from similar vendors from the locations with the least transportation energy needed.

The interface would work as follows: the consumer would enter what material is needed into a search engine, and the program would then show the product's availability as a function of its location relative to the consumer. This could greatly decrease the embodied energy of transportation of the product. Closer manufacturers would receive the highest ratings. A more advanced version of the program could be developed to calculate the greenhouse gas emissions from transport, producing the most ecologically efficient routes and transport methods. Another easily implemented modification of the Google Earth Transportation Optimization tool would be to encourage consumers to begin to factor in the cost of transportation into their shopping decisions. Google Earth could be used by consumers in finding locations that provide a certain item, check the price of the commodity and then factor that into a cost calculation that would include item cost plus the transportation cost. Consumers could input individual information concerning fuel costs, automobile mileage, depreciation and insurance to personalize the calculation. By providing consumers with exact information regarding the cost of a specific trip to purchase an item the market would operate closer to the ideal and also encourage more efficient consumer travel.

An example can best illustrate the functionality of the overlays needed to determine the optimal location, route and mode of transportation. In this case, the optimal means of transport for obtaining pineapples in Clarion Pennsylvania was chosen as illustration. Although, the pineapple is the $5^{\text {th }}$ most consumed fruit in the U.S. with an average per 
Joshua M. Pearce, Sara J. Johnson, and Gabriel B. Grant, "3D-Mapping Optimization of Embodied Energy of Transportation", Resources, Conservation and Recycling, 51 pp. 435-453, 2007.

capita consumption of 12.4 pounds per year, it is not grown commercially in Pennsylvania (U.S. Department of Agriculture, 2003). First, Google Earth could be used to input data from the U.S. Department of Agriculture (USDA) to locate the 80 countries and specific geographic areas of the world that produce and export pineapples, which include Thailand, the Philippines, Brazil, China, India, Costa Rica, Nigeria, Kenya, Mexico and Indonesia (USDA, 2003). Next, different transportation methods from each of these locations to Clarion could be analyzed to find the most cost efficient and energy efficient method of obtaining pineapples. The four methods of transport used in this illustration are truck, ship, train and aircraft. Using previously reported efficiency and emissions information from various organizations such as the Department of Transportation and the U.S. Federal Highway Administration, the least emissions route could be chosen.

\section{Results and Discussion for Technique 2:}

\section{A. Specific Example: Shipment of Pineapples from Hawaii to Clarion, Pennsylvania}

To illustrate how this system would function, the transportation of 1 ton of pineapples was simulated from Hawaii, where almost all commercially grown pineapples that appear in the U. S. originate (USDA, 2003). The most and least energy efficient direct routes and modes of transportation were found using Google Earth and can be seen in Fig. 4. Fuel consumption and emissions varies by transportation mode. No consistent fuel efficiency standards could be found because of the wide variation in efficiency between vehicles of the same type. In a completed full version, the fuel efficiencies for each individual vehicle or type of vehicle and carrier would be available to obtain exact quantities of emissions for a given route and mode. The following fuel efficiencies were used here to calculate fuel used and greenhouse gas emissions. Transportation via ship (140 tonmiles/gal) when it is possible is the most efficient means, followed by rail (100 tonmiles/gal), truck (41 ton-miles/gal) and airplane (5 ton-mile/gal) (Congressional Budget Office, 1982).

Based on these average ton-mile/gal for different modes, the least efficient route entails flying from Hawaii to Clarion. Please note that indirect routes (e.g. flying first to Atlanta then to Clarion) were ignored. The pineapples would travel 4,683 miles and use 936.6 gallons of fuel. The burning of this fuel releases over 18,000 pounds of $\mathrm{CO}_{2}$.

The most efficient route is a little more complicated. First, the ton of pineapples leaves Hawaii via ship and lands in San Francisco, CA. The ship will have traveled 2,388 miles and used 17.1 gallons of fuel. Next, the pineapples leave San Francisco on a single-unit diesel truck to Denver, CO. The truck travels 948.5 miles using 23.1 gallons. Then, from Denver, CO the pineapples traveled the remainder of its journey by train. The train traveled 1466 miles at 14.6 gallons. Thus, overall for this route the pineapples traveled 
Joshua M. Pearce, Sara J. Johnson, and Gabriel B. Grant, "3D-Mapping Optimization of Embodied Energy of Transportation", Resources, Conservation and Recycling, 51 pp. 435-453, 2007.

4,802.5 miles, only using 54.8 gallons of fuel releasing 523 pounds of $\mathrm{CO}_{2}$. In comparison to the least efficient route, the pineapples traveled a further distance but used 17 times less fuel and emissions. It should be noted that the amount of fuel calculated for each leg of the route includes propulsion energy, maintenance energy, vehicle manufacturing energy, construction energy, refinery losses and the energy used for empty movements and for the non-cargo weight of vehicles (Congressional Budget Office, 1982).

This example ignores the time aspect of using different transportation modes, which is often an important determinant of mode, particularly of perishable agricultural products like pineapples. This time aspect represents a limitation placed on the available modes of transportation for a given amount of goods to be transported. In addition, the costs associated with the different modes of transportation can result in the most energy efficient route being bypassed by the most economically efficient route. The use of Google Earth to at least determine the most energy efficient available routes will assist in reducing the embodied energy of transportation for goods. Although this was a hypothetical example, the ramifications of converting the majority of freight to optimal routes using the Google Earth client could be enormous.

\section{B. Generalized Applications for Manufacturers}

For manufacturers this tool becomes even more important as transportation costs become a larger fraction of the manufacturing costs of their products (Granahan, 2006). Historically, the transportation costs associated with manufacturing goods have been a relatively insignificant fraction of the final costs of a product. This can be seen by the global nature of the goods in any department store. The costs of transportation energy are so low (aggregate expenditures on freight are only 3.8\% percent of trade value in the U.S. (Hummels, 1999)) that other costs govern the location of manufacture. As transportation costs rise due to increases in fuel costs, the optimization of the embodied energy of transportation will become increasingly important for manufacturers that need parts and materials from numerous locations. Manufacturers could use maps produced by Google Earth to locate suppliers at closer geographic locations. Figure 5 shows an example map produced in Google Earth showing the companies in Ohio that manufacture goods from recycled vinyl (The Vinyl Institute, 2006). Both suppliers to the vinyl manufacturers and customers could utilize the maps to find sources for the materials or products that would entail either shorter or less emission-intensive routes.

Over 19 billion tons of freight were transported to and from U.S. businesses in 2002 (Bureau of Transportation Statistics [BTS], 2006). Out of more than 4.4 trillion ton-miles across the U.S., on average any one commodity was shipped 269 miles per ton (BTS, 2006). A relative minority of freight that travel the longest distances make up a large 
Joshua M. Pearce, Sara J. Johnson, and Gabriel B. Grant, "3D-Mapping Optimization of Embodied Energy of Transportation", Resources, Conservation and Recycling, 51 pp. 435-453, 2007.

fraction of the total ton-miles and offer the largest opportunities for reduced emissions. In 2002 , only $5 \%$ of shipments traveled more than 1000 miles, but this same $5 \%$ accounted for more than $1 / 3$ of the total ton-miles (BTS, 2006). The majority of emissions from this transport were from heavy-duty road vehicles, which comprised 19\% of mobile GHG emissions and 5\% of total emissions. Freight railroad and marine vessels combined make up only $1.3 \%$ of GHG emissions from all sources (Ang-Olson and Ostria, 2005). By reducing the distance and emission intensity of the transportation of manufactured goods, GHG emissions can be reduced.

\section{Advanced Applications for Manufacturers - Industrial Symbiosis}

Google Earth could perform a third function capable of optimizing material and resource consumption in parallel with the embodied energy of transportation by facilitating the creation of industrial symbiosis (IS). "Industrial symbiosis engages traditionally separate industries in a collective approach to competitive advantage involving physical exchange of materials, energy, water, and/or by-products. The keys to industrial symbiosis are collaboration and the synergistic possibilities offered by geographic proximity" (Chertow, 2000). Such a system collectively optimizes material and energy use at efficiencies beyond those achievable by any individual process alone. IS systems such as the web of materials and energy exchanges among companies in Kalundborg, Denmark have spontaneously evolved from a series of micro innovations over a long time scale (Ehrenfeld and Gertler, 1997); however, the engineered design and implementation of such systems from a macro planner's perspective, on a relatively short time scale, proves challenging. Often, access to information on available by-products is non-existent. These by-products are considered waste and typically not traded or listed on any type of exchange.

Google Earth could provide a GIS-based framework for mapping industrial processes, and their associated material and energy flows, to help discover opportunities for byproduct synergies. Software tools such as the U.S. Environmental Protection Agency's Facility Synergy Tool (FaST) and Bechtel's (now Nexant's) Integrated Material Exchange (IME) Tool have been experimented with on local and regional scales, but have historically been proprietary for a given project. For example, FaST was used for an Eco-Industrial Park Planning Case Study in Burlington Vermont (Industrial Economics, 1998). Although the tool was shared publicly, the much needed industry data was not successfully shared between users. Importunely, FaST is no longer supported and does not run on updated computers. Google Earth is capable of sharing information collaboratively and publicly and does not suffer from geographical restrictions or reliance on commercial software such as Microsoft Access. 
Joshua M. Pearce, Sara J. Johnson, and Gabriel B. Grant, "3D-Mapping Optimization of Embodied Energy of Transportation", Resources, Conservation and Recycling, $\mathbf{5 1}$ pp. 435-453, 2007.

Preliminarily, Google Earth can be used to identify processes or production facilities, as it provides a geographical directory of companies that have been "tagged" by Google Earth's open source user community. This functionality is already utilized by Eckelman and Chertow at Yale University in workshop exercises to teach leadership groups how to identify potential synergies. Future work is needed to determine how material and energy flows may be tagged and more sophisticated algorithms can be employed to optimize flows and identify potential by-product synergies.

\section{Generalized Applications for Architects and Designers}

The embodied energy for transportation tool would also be useful to architects. Currently, an enormous interest is being taken in Leadership in Energy and Environmental Design (LEED) ratings for buildings. The LEED Green Building Rating System is a voluntary, consensus-based national standard for developing high-performance, sustainable buildings. LEED provides an evolving framework for assessing building performance and meeting sustainability goals. LEED emphasizes state of the art strategies for sustainable site development, water savings, energy efficiency, materials selection and indoor environmental quality (U.S. Green Building Council, 2006). LEED is built on a point (credit) system, where the "greener" and more energy efficient a building is, the more points and the higher level of certification achieved (platinum, gold, silver and 'certification').

Several of the LEED points are based on where a material that makes up the building is manufactured, and this could be facilitated by the database of material locations created for Google Earth. The U.S. Green Building Council (USGBC) gives points for local materials in order to increase demand for building materials and products that are extracted and manufactured within the region, thereby supporting the regional economy and reducing the environmental impacts resulting from transportation (USGBC, 2002). To earn a LEED credit in Materials and Resources (MR) Credit 5.1, a minimum of 20\% of a building's materials and products must be manufactured regionally within a radius of 500 miles, where manufacturing refers to the final assembly of the components into the building product that is installed by the tradesmen. For MR Credit 5.2, of the regionally manufactured materials documented for MR Credit 5.1, a minimum of $50 \%$ of the building's materials and products must be extracted, harvested, or recovered (as well as manufactured) within 500 miles of the project site. In addition, building designers must establish a project goal for locally sourced materials, as well as identifying materials and contracting with the material suppliers that can achieve this goal. During construction, they must ensure that the specified local materials are installed and quantify the total percentage of local materials installed (USGBC, 2002). 
Joshua M. Pearce, Sara J. Johnson, and Gabriel B. Grant, "3D-Mapping Optimization of Embodied Energy of Transportation", Resources, Conservation and Recycling, 51 pp. 435-453, 2007.

All phases of construction would benefit from having good real time data of resources and recycling sites. For example, aggregate is used in building construction to provide bulk, strength, support and wear resistance. The cost of construction aggregate to the end user is strongly influenced by the cost of transporting processed aggregate from the production site to the construction site (Robinson and Kapo, 2004; Robinson, Menzie, and Hyun, 2004). Robinson and Kapo completed a geographic information systems analysis for determining construction aggregate recycling sites using existing transportation networks and population (2004). This type of work could be integrated into the Google Earth overlays. In addition, for LEED credits MR 2.1 and MR 2.2, building designers must develop and implement a waste management plan and quantify material diversion goals. For credit MR 2.1 they must recycle and/or salvage at least $50 \%$ of construction, demolition and land clearing waste and for credit MR 2.2 recycle and/or salvage an additional 25\% (75\% total) of construction, demolition and land clearing waste (USGBC, 2002).

The USGBC has three goals for recycling and salvaging construction materials: i) divert construction, demolition and land clearing debris from landfill disposal, ii) redirect recyclable recovered resources back to the manufacturing industry, and iii) redirect reusable materials to appropriate sites. All of these goals can be more easily met with a Google Earth overlay of all available recycling and salvage locations. This method can be seen in Figure 6, which is a map created by Google Earth showing the recycling locations in Clarion County, PA and contact information for the various recycling businesses.

\section{Discussion}

All of the above suggestions for functionality of the Google Earth Transportation Optimization Tool would reduce energy use. The quantitative savings for each of the suggestions is challenging to predict because the methods are based on compliance of decision makers to utilize specific routes, products, or modes of transportation with reduced embodied energy. Some more environmentally-conscious drivers might alter their driving habits to closely maintain their vehicles optimal velocity, while others might completely ignore this information if it were available. Compliance would vary even for a single decision maker. For example, a decision maker that is late to work is unlikely to reduce speed to save energy and money, whereas that same driver may welcome additional information that will enable him to get to the next gas station when he is running low on gas. Today, in a large part decision makers simply do not have the information available concerning the embodied energy of transportation to make complete decisions. Particularly at the small scale, consumers do not even have easy access to the total costs of transportation in order to make informed rational decisions. The Google Earth Transportation Optimization Tool would correct this information gap and provide a means of significantly reducing energy use. Future research is needed to 
Joshua M. Pearce, Sara J. Johnson, and Gabriel B. Grant, "3D-Mapping Optimization of Embodied Energy of Transportation", Resources, Conservation and Recycling, $\mathbf{5 1}$ pp. 435-453, 2007.

quantify the potential savings for each of the methods outlined in this report: personal route optimization, fleet route optimization, optimal vehicle speed, enhanced driver education and information availability, shipping transportation mode optimization, enhanced LCA for products, industrial symbiosis increases and LEED improvements.

\section{Conclusions}

This paper completed an analysis of Google Earth, an information service that provides imagery and 3D data depicting the entire Earth, as a novel method of navigating information to conserve travel-related fuels. First, this paper showed that at the individual driver level, Google Earth could be used to map the route that uses the least fuel between two locations and enable drivers to chart a course that maintains their vehicle at its individual maximum fuel efficiency velocity. This functionality would have a secondary benefit of encouraging more efficient driving by helping drivers better understand the externalities associated with their travel. The data on the fuel used in a trip could be converted into monetary units based on the current price of gasoline to encourage conservation on economic terms or pollution, GHG emission weights, or ecological footprints on environmental/ethical terms. Similarly, the same analysis indicated that Google Earth would be useful to optimize fleet vehicle routes such as garbage or recycling collection trucks. Secondly, overlays in KML of raw material and products availability as a function of location and modes of transportation as a function of emissions could be developed. These overlays would enable manufacturers to optimize the life cycle of their products by minimizing the embodied energy of transportation by calculating the most efficient transportation methods (truck, train, boat, or airplane) and travel routes for finished products and raw materials. These same overlays would be useful for identifying industrial symbiosis opportunities further reducing environmental impact of manufacturing. Finally, Google Earth used in this capacity would also be useful for architects to obtain LEED rating points for the green design of buildings. By utilizing Google Earth as outlined in this paper we can significantly reduce fossil fuel consumed, GHG emissions and overall environmental impacts due to transportation.

\section{Acknowledgements}

We would like to thank our anonymous reviewers who have provided helpful comments on the refinement of this paper.

\section{References}

Angelelli E., Speranza M.G. 2002. The application of a vehicle routing model to a wastecollection problem: two case studies. Journal of the Operational Research Society, 53(9):944-952. 
Joshua M. Pearce, Sara J. Johnson, and Gabriel B. Grant, "3D-Mapping Optimization of Embodied Energy of Transportation", Resources, Conservation and Recycling, $\mathbf{5 1}$ pp. 435-453, 2007.

Ang-Olson, J. and Ostria, S. 2005. Assessing the Effects of Freight Movement on Air Quality at the National and Regional Level, Chapter 2: National Freight Transportation and Emissions, prepared for the U.S. Federal Highway Administration, Office of Natural and Human Environment, available: http://www.fhwa.dot.gov/environment/freightaq/index.htm

Ayres, R. U. 1995. Life cycle analysis: A critique. Resources, Conservation and Recycling, 14(3-4): 199-223.

Ballou, R. H. 1990. A Continued Comparison of Several Popular Algorithms for Vehicle Routing and Scheduling. Journal of Business Logistics. 11(1): 111-127.

Bentley, R. W. 2002. Global oil \& gas depletion: an overview. Energy Policy, 30: 189205.

Biever, C. 2005. Will Google Help Save the Planet? New Scientist, 187(2512): 28-29.

Boulos, M. N.K. 2005. Web GIS in practice III: creating a simple interactive map of England's Strategic Health Authorities using Google Maps API, Google Earth KML, and MSN Virtual Earth Map Control. International Journal of Health Geographics, 4: 22.

Bowerman, R., Hall, B. and Calamai, P. 1995. A Multi-Objective Optimization Approach to Urban School Bus Routing: Formulation and Solution Method. Transportation Research Part A: Policy and Practice. 29A(2): 107-123.

Bureau of Transportation Statistics. 2006. "The Nation's Freight”, available: http://www.bts.gov/publications/freight in america/html/nations freight.html

Butler, D. 2005. Enthusiast uses Google to reveal Roman Ruins. Nature.com, doi:10.1038/news050912-6.

Caldeira, K. and Wickett, M. E. 2003. Oceanography: Anthropogenic carbon and ocean $\mathrm{pH}$, Nature, 425: 365.

Chertow, M. R. 2000. Industrial Symbiosis: Literature and Taxonomy, Annual Review of Energy and the Environment, 25: 313-337. 
Joshua M. Pearce, Sara J. Johnson, and Gabriel B. Grant, "3D-Mapping Optimization of Embodied Energy of Transportation", Resources, Conservation and Recycling, $\mathbf{5 1}$ pp. 435-453, 2007.

Chi, G. and Stone, B. 2005. Sustainable Transport Planning: Estimating the Ecological Footprint of Vehicle Travel in Future Years, Journal of Urban Planning and Development, 131: 170-180.

Congressional Budget Office, 1982. "Energy Use in Freight Transportation", available: http://www.cbo.gov/showdoc.cfm?index $=5330 \&$ sequence $=0$.

Ehrenfeld, J. and Gertler, N. 1997. Industrial Ecology in Practice: The Evolution of Interdependence at Kalundborg, Journal of Industrial Ecology 1(1): 67.

Energy Information Administration. 2006. Fuel and Energy Source Codes and Emission Coefficients, available: http://www.eia.doe.gov/oiaf/1605/factors.html

Energy Information Administration. 2006b. Transportation Energy Consumption Surveys Energy Used by Vehicles, Chapter 3. Vehicle-Miles Traveled, available: http://www.eia.doe.gov/emeu/rtecs/chapter3.html

Google Earth 2006. Google Earth Homepage, available: http://earth.google.com/

González, B., Adenso-Díaz, B. and González-Torre, P. L. 2002. A Fuzzy Logic Approach for the Impact Assessment in LCA, Resources, Conservation and Recycling, 37(1): 61-79.

Granahan, T. 2006. As Transportation Costs Surge, Railroads Keep On Truckin'. Manufacturing.net, available: http://www.manufacturing.net/article/CA6360790.html

Gregory, J.M., Huybrechts, P., and Raper, S.C. 2004. Threatened Lose of the Greenland Ice-sheet. Nature. 428: 616.

Hansen, J., Sato, M., Ruedy, R., Lacis, A., and Oinas, V. 2000. Global warming in the twenty-first century: An alternative scenario. Proceedings of the National Academy of Sciences in the United States of America. 97(18): 9875-9880.

Heavenrich, R. M. 2006. Light-Duty Automotive Technology and Fuel Economy Trends: 1975 through 2006, United States Environmental Protection Agency, EPA420-R-06-011.

Hoffert, M. I., Caldeira, K., Benford, G., Criswell, D.R., Green, C., Herzog, H., Jain, A.K., Kheshgi, H.S., Lackner, K.S., Lewis, J.S., Lightfoot, H.D., Manheimer, W., Mankins, J.C., Mauel, M.E., Perkins, L.J., Schlesinger, M.E.,Volk, T., and Wigley, 
Joshua M. Pearce, Sara J. Johnson, and Gabriel B. Grant, "3D-Mapping Optimization of Embodied Energy of Transportation", Resources, Conservation and Recycling, $\mathbf{5 1}$ pp. 435-453, 2007.

T.M.L., 2002. Advanced Technology Paths to Global Climate Stability: Energy for a Greenhouse Planet. Science, 298: 981-987.

Hummels, D., 1999. Towards a geography of trade costs. University of Chicago, mimeograph.

Hungate, B.A, Stiling, P.D., Dijkstra, P., Johnson, D.W., Ketterer, M.E., Hymus, G.J., Hinkle, C.R., and Drake, B.G. 2004. $\mathrm{CO}_{2}$ Elicits Long-term Decline in Nitrogen Fixation. Science, 304: 1291.

Hunhammar, S., 1995. Cycling residues. Potential for increased transportation demands due to recycling of materials in Sweden. Resources, Conservation and Recycling, 15(1): 21-31.

Industrial Economics Inc. 1998. Applying Decision Support Tools for Eco-Industrial Park Planning: A Case Study in Burlington Vermont, Cambridge, MA.

INFORM Inc. 2006. Facts on Greening Garbage Trucks: New Technologies for Cleaner Air, available: http://www.informinc.org/fact ggt.php

The Intergovernmental Panel on Climate Change (IPCC). 1995. Climate change 1995: the science of climate change, summary for policy makers and technical summary and IPCC Second Assessment Report: Climate Change. United Nations Environment Program and World Meteorological Organization, New York.

The Intergovernmental Panel on Climate Change (IPCC). 2001. Summary for Policymakers, Climate Change 2001: Impacts, Adaptation, and Vulnerability. United Nations Environment Program and World Meteorological Organization, New York.

Koelle, K., Rodo, X., Pascual, M., Yunus, M., and Mostafa, G. 2005. Refractory Periods and Climate Forcing in Cholera Dynamics. Nature, 436: 696-700.

Kovats, R.S., Menne, B., McMichael, A.J., Bertollini, R. and Soskolne, C. (eds) 1999. Early Human Health Effects of Climate Change and Stratospheric Ozone Depletion in Europe. Third Ministerial Conference on Environment and Health, World Health Organization: London.

Krajick, K. 2004. All Down hill From Here? Science, 303:1600-1602. 
Joshua M. Pearce, Sara J. Johnson, and Gabriel B. Grant, "3D-Mapping Optimization of Embodied Energy of Transportation", Resources, Conservation and Recycling, $\mathbf{5 1}$ pp. 435-453, 2007.

McKibbon, B. 2003. My Mileage is Better Than Your Mileage: An all-American idea for getting Americans to take gas consumption seriously. Orion, Small Change, January/February.

National Energy Board. 2005. Project Enable: Annual Report 2004 to Parliament, National Energy Board: Calgary, Alberta, Canada, available: http://www.neb.gc.ca/Publications/AnnualReports/2004/AnnualReport2004 e.pdf

Nourbakhsh, I., Sargent, R., Wright, A., Cramer, K., McClendon, B., Jones, M. 2006. Mapping disaster zones. Nature, 439(7078): 787-788.

Nuortioa, T., Kytöjokib, J., Niskaa, H., and Bräysyb, O. 2006. Improved route planning and scheduling of waste collection and transport. Expert Systems with Applications 30(2):223-232.

Pattnaik S. B., Mohan S., Tom V. M. 1998. Urban Bus Transit Route Network Design Using Genetic Algorithm. Journal of Transportation Engineering 124(4): 368-375.

Pearce, J. 2002. Photovoltaics - A Path to Sustainable Futures. Futures, 34(7): 663-674.

Pearce J. M. and Hanlon, J. T. 2006. Energy Conservation From Systematic Tire Pressure Regulation, Energy Policy, doi:10.1016/j.enpol.2006.07.006.

Pearce J. and Lau, A. 2002. Net Energy Analysis For Sustainable Energy Production From Silicon Based Solar Cells, In R. Cambell-Howe editor, Proceedings of American Society of Mechanical Engineers Solar 2002: Sunrise on the Reliable Energy Economy.

Pearce, J., Uhl, C., Mandryk, A., Matalavage, D., Vischer, C., Byrne, L., and Eisenfeld, S. 2001. The Mueller Report: Moving Beyond Sustainability Indicators to Sustainability Action. The Green Destiny Council: University Park, PA.

Penner, J. 2004. The Cloud Conundrum, Nature, 432: 962-963.

Ristinen, R. A. and Kraushaar, J. J. 1999. Energy and the Environment. John Wiley and Sons, Inc.: New York.

Robinson, G. R. Menzie, W. D. and Hyun H. 2004. Recycling of construction debris as aggregate in the Mid-Atlantic Region, USA. Resources, Conservation and Recycling, 42 (3): $275-294$ 
Joshua M. Pearce, Sara J. Johnson, and Gabriel B. Grant, "3D-Mapping Optimization of Embodied Energy of Transportation", Resources, Conservation and Recycling, $\mathbf{5 1}$ pp. 435-453, 2007.

Robinson, G.R. and Kapo K. E. 2004. A GIS analysis of suitability for construction aggregate recycling sites using regional transportation network and population density features. Resources, Conservation and Recycling, 42(4): 351-365.

Rose, A. 1979. Global view of solar energy in rational units, Physica Status Solidi (A) 56: 11-26.

Sahoo, S., Kim, S., Kim, B., Kraas, B., and Popov, A. 2005. Routing Optimization for Waste Management. Interface 35(1): 24-36.

Schar, C., Vidale, P.L., Luthi, D., Frei, C., Haberli, H., Liniger, M.A. and Appenzeller, C. 200. The Role of Increasing Temperature Variability in European Summer Heatwaves. Nature, 427: 332-336.

Schiermeier, Q. 2004. A Rising Tide. Nature, 428:114-115.

Stocker, T. 2004. Models Change their Tune. Nature, 430: 737-738.

Suh, Y. and Rousseaux, P. 2002. An LCA of alternative wastewater sludge treatment scenarios. Resources, Conservation and Recycling, 35(3): 191-200.

Thomas, C.D., Cameron, A., Green, R.E., Bakkenes, M., Beaumont, L.J., Collingham, Y.C., Erasmus, B.F.N., de Siquelra, M.F., Grainger, A., Hannah, L., Hughes, L., Huntley, B., van Jaarsveld, A.S., Midgley, G.F., Miles, L., Ortega-Huerta, M.A., Peterson, A.T., Phillips, O.L., and Williams, S.E. 2004. Extinction Risk from Climate Change. Nature, 427:145-148.

U.S. Department of Agriculture. 2003. Fruit and Tree Nuts Outlook/FTS-307: 12-17.

U.S. Department of Energy. 2004. Transportation Energy Data Book: Edition 24, available: http://cta.ornl.gov/data

U.S. Environmental Protection Agency. 2006. Inventory of U.S. Greenhouse Gas Emissions and Sinks: 1990-2004, U.S. Environmental Protection Agency: Washington, D.C.

U.S. Green Building Council. 2002. Green Building Rating System For New Construction \& Major Renovations (LEED-NC) Version 2.1, available: https://www.usgbc.org/Docs/LEEDdocs/LEED RS v2-1.pdf 
Joshua M. Pearce, Sara J. Johnson, and Gabriel B. Grant, "3D-Mapping Optimization of Embodied Energy of Transportation", Resources, Conservation and Recycling, $\mathbf{5 1}$ pp. 435-453, 2007.

U. S. Green Building Council. 2006. LEED: Leadership in Energy and Environmental Design, available: http://www.usgbc.org/LEED/LEED main.asp

The Vinyl Institute. 2006. Directory of US and Canadian Companies Manufacturing Products from Recycled Vinyl, available: http://www.vinylinfo.org/database/vinyldata/

Wackernagel, M. and W. Rees. 1994. Our Ecological Footprint : Reducing Human Impact on the Earth, New Society Publishers: Gabriola Island, B.C. Canada.

Wang, C. Even, J. C. and Adams, S. K. 1995. A mixed-integer linear model for optimal processing and transport of secondary materials. Resources, Conservation and Recycling, 15(1): 65-78.

Yergin, D. 1992. The Prize: The Epic Quest for Oil, Money and Power, Touchstone: New York. 
Joshua M. Pearce, Sara J. Johnson, and Gabriel B. Grant, "3D-Mapping Optimization of Embodied Energy of Transportation", Resources, Conservation and Recycling, 51 pp. 435-453, 2007.

\section{Tables and Figures}

\begin{tabular}{|l|c|c|c|c|}
\hline End-use Sector & $\mathbf{1 9 9 0}$ & $\mathbf{1 9 9 0} \%$ & $\mathbf{2 0 0 4}$ & $\mathbf{2 0 0 4} \%$ \\
\hline Transportation & $1,464.4$ & $31 \%$ & $\begin{array}{c}1,860 . \\
2\end{array}$ & $33 \%$ \\
\hline Industrial & $1,528.3$ & $33 \%$ & $\begin{array}{c}1,595 . \\
0\end{array}$ & $28 \%$ \\
\hline Residential & 922.8 & $20 \%$ & $\begin{array}{c}1,166 . \\
8\end{array}$ & $21 \%$ \\
\hline Commercial & 753.1 & $16 \%$ & 983.1 & $18 \%$ \\
\hline Total & $\mathbf{4 , 6 6 8 . 6}$ & $\mathbf{1 0 0 \%}$ & $\mathbf{5 6 0 5 . 2}$ & $\mathbf{1 0 0 \%}$ \\
\hline
\end{tabular}

Table 1. $\mathrm{CO}_{2}$ emissions from combustion of fossil fuel by end-use sector for 1990 and 2004 ( $\mathrm{Tg}\left[10^{6}\right.$ metric tons] $\mathrm{CO}_{2}$ ) (U.S. EPA, 2006). 
Joshua M. Pearce, Sara J. Johnson, and Gabriel B. Grant, "3D-Mapping Optimization of Embodied Energy of Transportation", Resources, Conservation and Recycling, 51 pp. 435-453, 2007.

\begin{tabular}{|l|c|c|c|c|}
\hline Fuel Type & $\mathbf{1 9 9 0}$ & $\mathbf{1 9 9 0} \%$ & $\mathbf{2 0 0 4}$ & $\mathbf{2 0 0 4} \%$ \\
\hline Gasoline & 964.9 & $61 \%$ & $1,174$. & $60 \%$ \\
& & & 3 & \\
\hline Diesel & 270.0 & $17 \%$ & 443.4 & $23 \%$ \\
\hline Jet Fuel & 220.4 & $14 \%$ & 237.4 & $12 \%$ \\
\hline Residual Fuel Oil & 79.3 & $5 \%$ & 54.6 & $<3 \%$ \\
\hline Natural Gas & 35.9 & $<3 \%$ & 37.4 & $<2 \%$ \\
\hline Total & $\mathbf{1 , 5 7 0}$. & $\mathbf{1 0 0 \%}$ & $\mathbf{1 9 4 7 . 1}$ & $\mathbf{1 0 0 \%}$ \\
& $\mathbf{5}$ & & & \\
\hline
\end{tabular}

Table 2. $\mathrm{CO}_{2}$ Emissions from Fossil Fuel Combustion in Transportation for 2004 (Tg [10 ${ }^{6}$ metric tons $] \mathrm{CO}_{2}$ ) (from U.S. EPA, 2006). 
Joshua M. Pearce, Sara J. Johnson, and Gabriel B. Grant, "3D-Mapping Optimization of Embodied Energy of Transportation", Resources, Conservation and Recycling, $51 \mathrm{pp}$. 435-453, 2007.

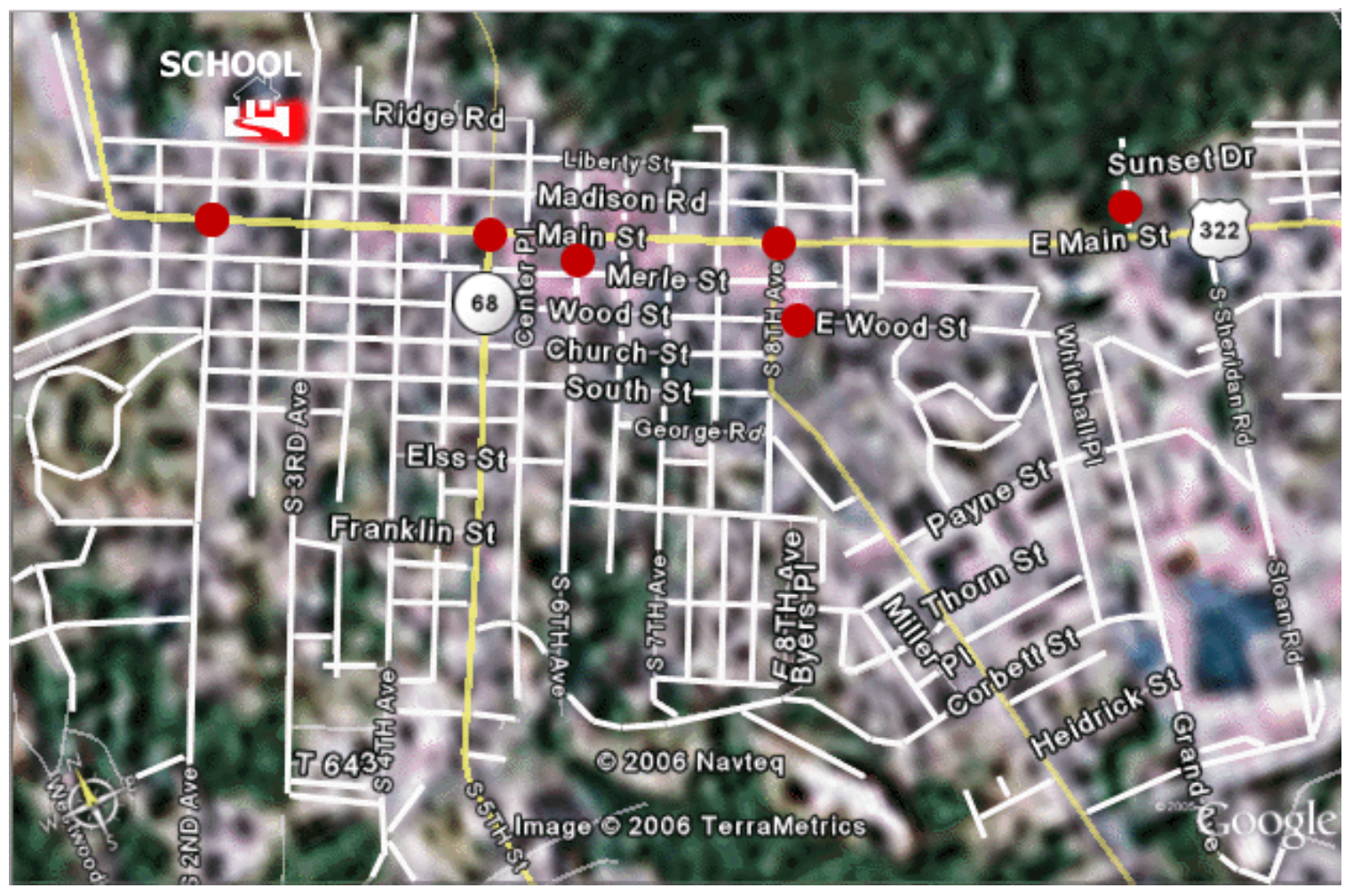

Figure 1. Image of streets in Clarion, PA created by Google Earth. The circles signify traffic lights. 
Joshua M. Pearce, Sara J. Johnson, and Gabriel B. Grant, "3D-Mapping Optimization of Embodied Energy of Transportation", Resources, Conservation and Recycling, 51 pp. 435-453, 2007.

MPH vs MPG

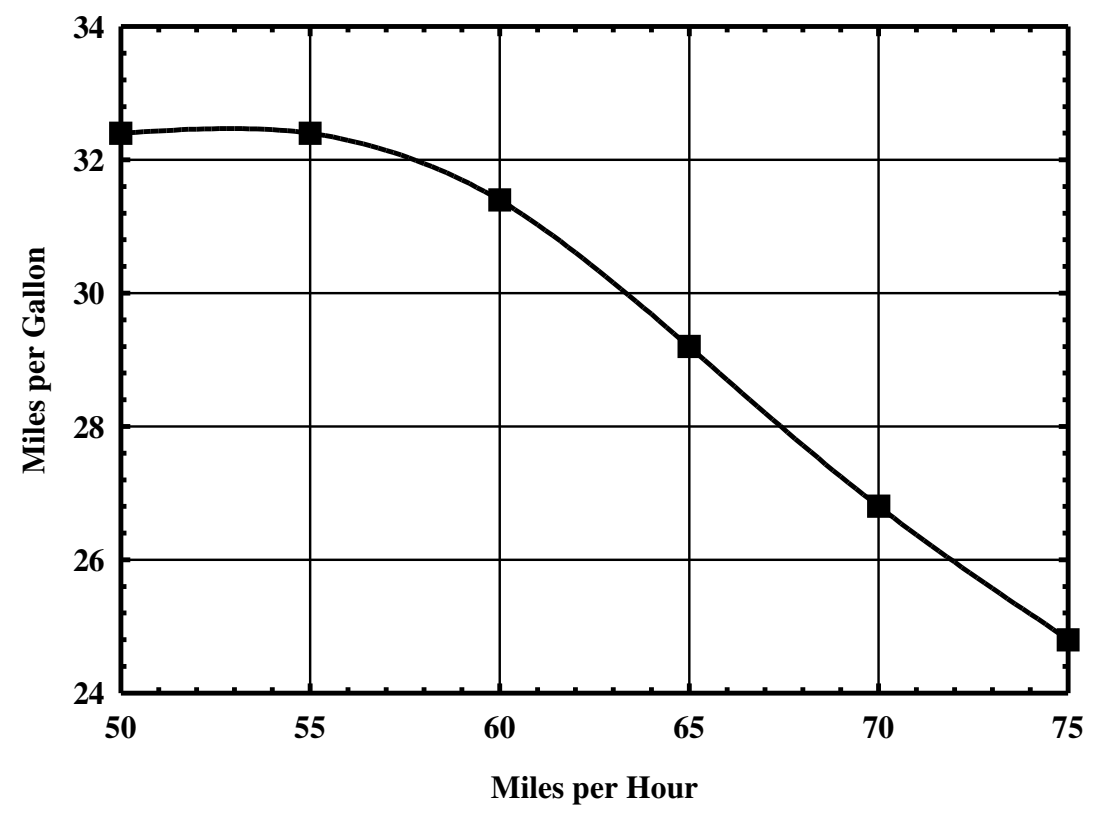

Figure 2. MPH vs MPG for a typical American automobile. The graph is based on information published in the Transportation Energy Data Book: Edition 23, Table 4.24. 
Joshua M. Pearce, Sara J. Johnson, and Gabriel B. Grant, "3D-Mapping Optimization of Embodied Energy of Transportation", Resources, Conservation and Recycling, 51 pp. 435-453, 2007.

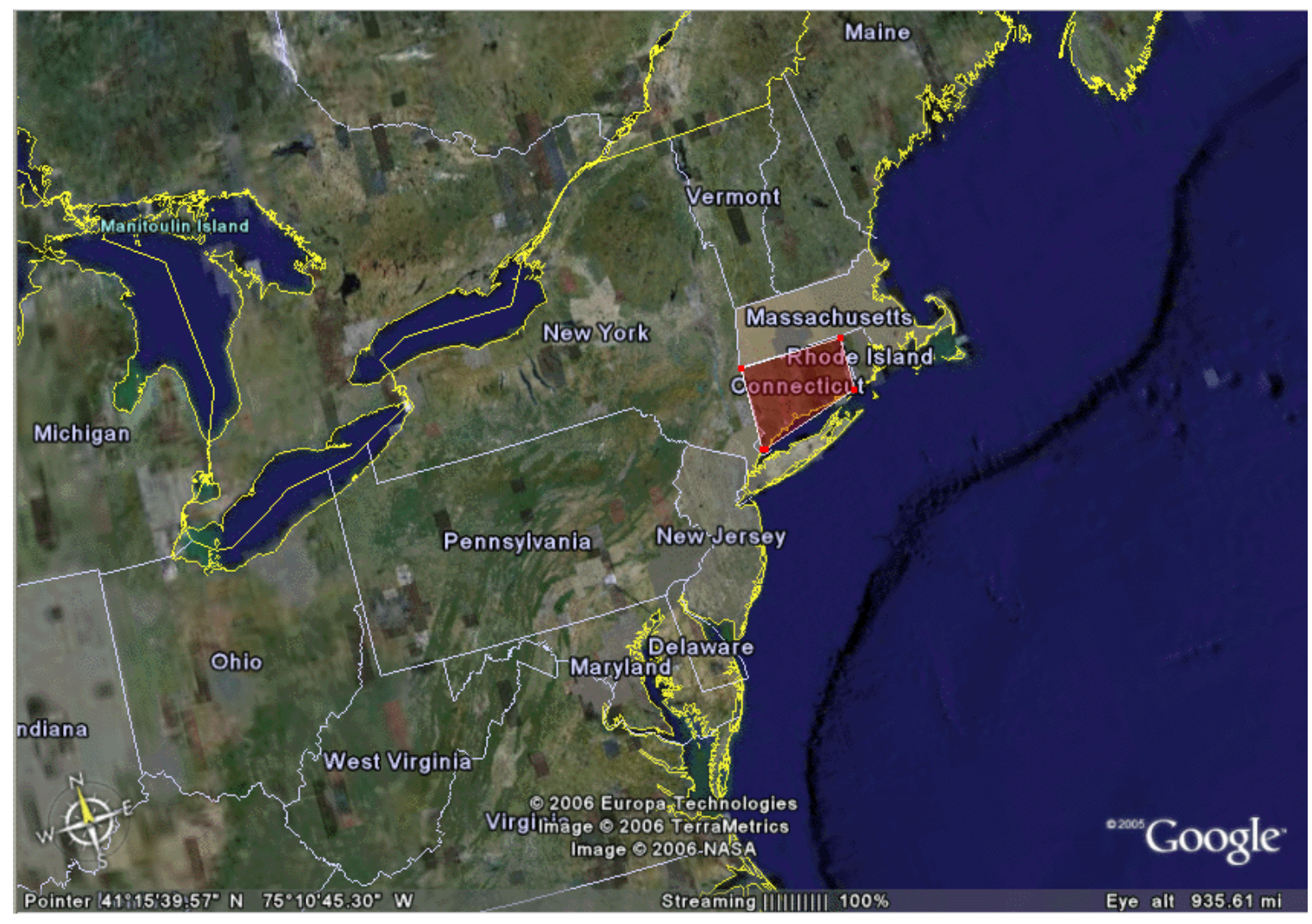

Figure 3. The land area needed to sequester the $\mathrm{CO}_{2}$ emissions from all the garbage trucks $(\mathbf{1 3 6 , 0 0 0 )}$ in the U.S. for one year is 1.5 million hectare (about 5,720 square miles), which is approximately the size of Connecticut. 
Joshua M. Pearce, Sara J. Johnson, and Gabriel B. Grant, "3D-Mapping Optimization of Embodied Energy of Transportation", Resources, Conservation and Recycling, 51 pp. 435-453, 2007.

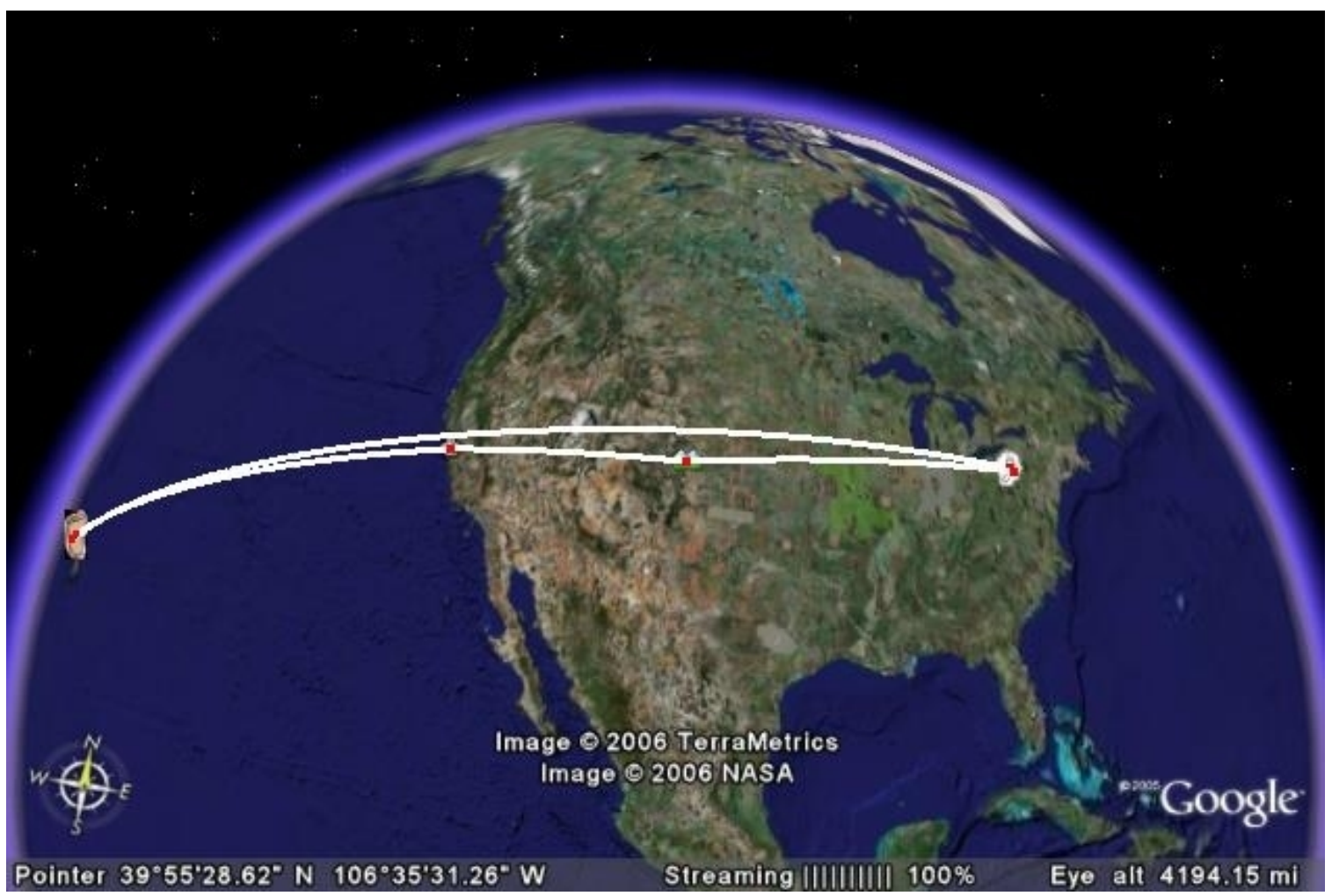

Figure 4. Google Earth Map of two example routes for transporting pineapples from Hawaii to Clarion Pennsylvania. 
Joshua M. Pearce, Sara J. Johnson, and Gabriel B. Grant, "3D-Mapping Optimization of Embodied Energy of Transportation", Resources, Conservation and Recycling, 51 pp. 435-453, 2007.

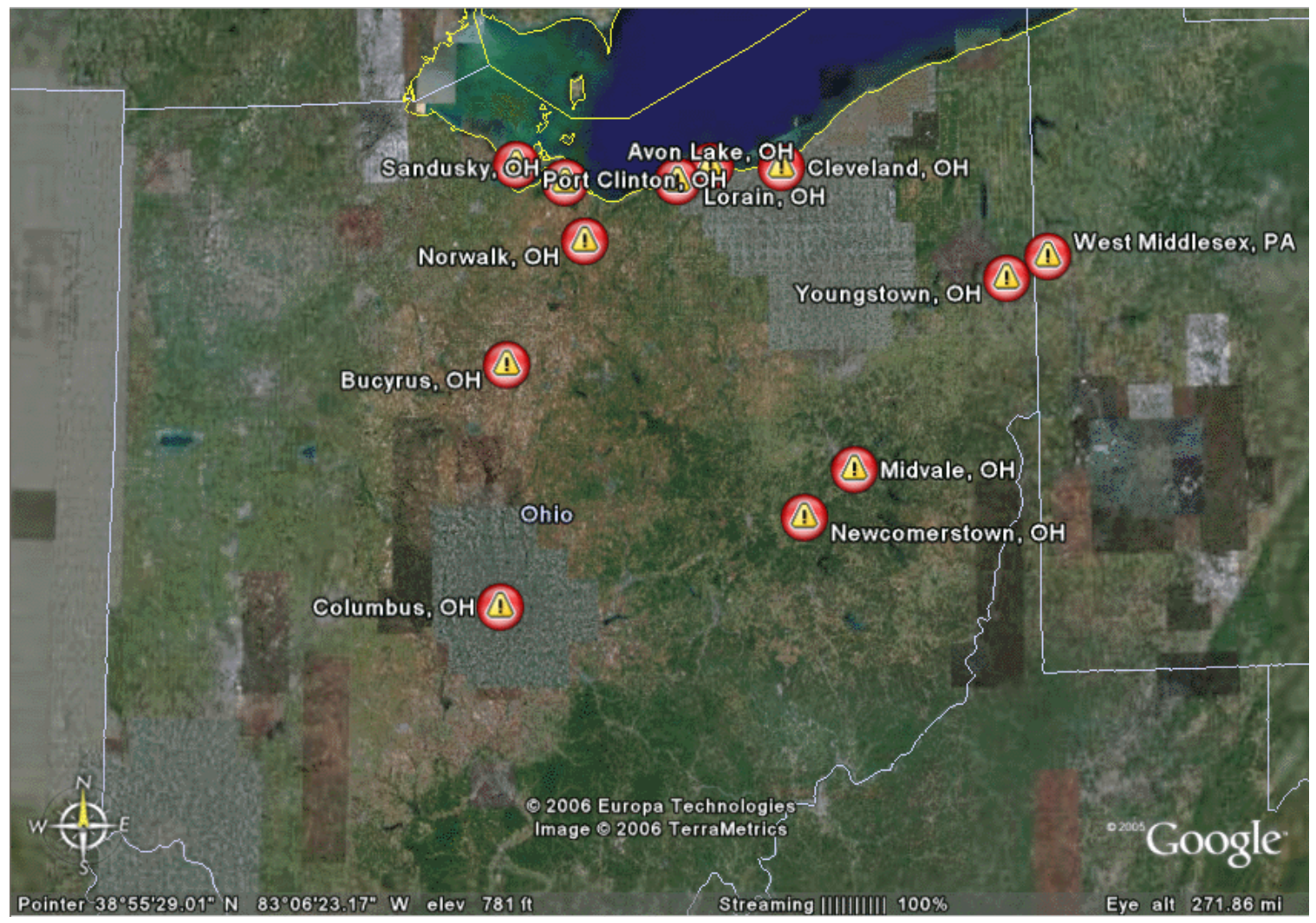

Figure 5. A map produced in Google Earth showing the companies in Ohio that manufacture goods from recycled vinyl (The Vinyl Institute, 2006). 
Joshua M. Pearce, Sara J. Johnson, and Gabriel B. Grant, "3D-Mapping Optimization of Embodied Energy of Transportation", Resources, Conservation and Recycling, 51 pp. 435-453, 2007.

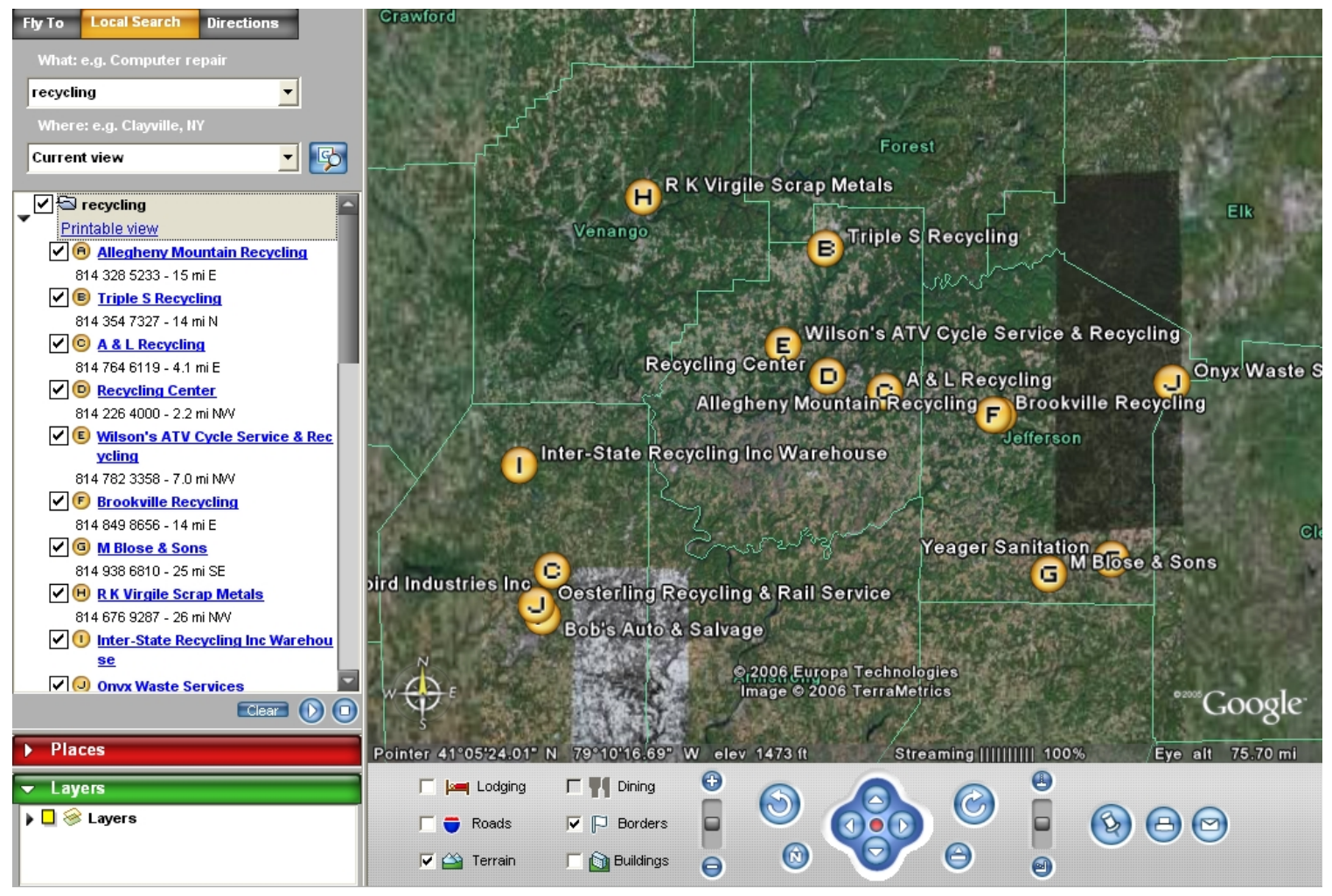

Figure 6. A map created by Google Earth showing the recycling locations in Clarion County, PA and contact information for the various businesses. 